Article

\title{
The Paris Agreement: Short-Term and Long-Term Effectiveness
}

\author{
Guri Bang ${ }^{1}$, Jon Hovi ${ }^{2, *}$ and Tora Skodvin ${ }^{2}$ \\ ${ }^{1}$ Center for International Climate and Environmental Research, 0349 Oslo, Norway; E-Mail: guri.bang@cicero.oslo.no \\ ${ }^{2}$ Department of Political Science, University of Oslo, 0317 Oslo, Norway; E-Mails: jon.hovi@stv.uio.no (J.H.), \\ tora.skodvin@stv.uio.no (T.S.) \\ * Corresponding author
}

Submitted: 10 April 2016 | Accepted: 9 July 2016 | Published: 8 September 2016

\begin{abstract}
The 2015 Paris Agreement was widely greeted with enthusiasm. We assess the short-term and long-term potential effectiveness of Paris. Concerning short-term effectiveness, we contend that while Paris scores high on participation, and reasonably high on the depth of the parties' commitments (ambition), its Achilles' heel will likely be compliance. Concerning long-term effectiveness, we argue that Paris does little to restructure states' incentives so as to avoid free riding. At worst, it might end up as a failure, much like Kyoto did. On the other hand, domestic and international norms could continue to develop in a direction that makes it more and more difficult for individuals, firms, and states alike to ignore the plea to limit and reduce their carbon footprints. Technological progress that gradually reduces abatement costs, combined with leadership by major emitters such as the United States, might further strengthen climate cooperation and enhance other countries' willingness to follow through. However, deep political polarization continues to represent a significant barrier to U.S. leadership on climate change.
\end{abstract}

\section{Keywords}

climate change mitigation; climate cooperation; effectiveness, international leadership; Paris Agreement; U.S.

\section{Issue}

This article is part of the issue "Climate Governance and the Paris Agreement", edited by Jon Hovi and Tora Skodvin (University of Oslo, Norway).

(C) 2016 by the authors; licensee Cogitatio (Lisbon, Portugal). This article is licensed under a Creative Commons Attribution 4.0 International License (CC BY).

\section{Introduction}

While the expectations for the 2015 Paris climate change meeting were modest, the outcome-the Paris Agreement-was widely greeted with enthusiasm (e.g., Brun, 2016; Dimitrov, 2016). A bottom-up agreement, Paris requires countries to submit nationally determined contributions (NDCs) to reducing global emissions. It also includes a set of mechanisms for ratcheting up these NDCs over time. Partly because the NDCs are not legally binding, Paris does not include any enforcement measures. Importantly, therefore, the intention is that once key countries make first steps towards cutting their emissions, others will follow suit.

In this paper, we assess the short-term and longterm effectiveness of the Paris Agreement. By short- term effectiveness we mean the extent to which Paris may be expected to contribute to reducing global emissions in its first five-year period. By long-term effectiveness we mean the extent to which it is likely to reduce global emissions in a time perspective longer than five years.

Section 2 clarifies the criteria we use to assess the Paris Agreement's effectiveness. Sections 3 and 4 consider the Agreement's short-term and long-term effectiveness, respectively. We argue that its short-term effectiveness will likely be limited. Moreover, its longterm effectiveness remains uncertain. At worst, the Agreement might prove to be a failure. At best, it might cause a race to the top that eventually makes it very effective in the long term. The outcome will likely depend on, among other things, whether major emitters 
prove able and willing to take the lead. In section 5 we discuss the prospects for such leadership by one major emitter that has a particularly important role as a first mover - the United States. Finally, section 6 concludes.

\section{Criteria for Evaluation}

To be effective, a climate agreement must satisfy three requirements (Barrett, 2003). First, it must attract broad participation to ensure that most (or preferably all) of the world's anthropogenic greenhouse gas (GHG) emissions are covered by the agreement. Second, to make a real difference for curbing climate change the agreement must reflect high ambitions, in the sense that it must commit the participating countries to deep emissions reductions. Finally, the agreement must achieve high compliance rates, that is, the participating countries must actually meet their emissions reduction targets.

We emphasize that these three conditions for effectiveness apply to all climate agreements, regardless of their type. In particular, they apply regardless of whether the participating countries' commitments to curbing emissions are determined top down or bottom up. They also apply regardless of the extent to which the participating countries are held responsible for their actions internationally or only at the national level.

Importantly, satisfying one or two requirements is not enough. In the words of Simmons (1998, p. 78), "while compliance may be necessary for effectiveness, there is no reason to consider it sufficient". The same can be said about broad participation and deep commitments: Whereas each condition is necessary, all three must be fulfilled to ensure effectiveness.

Conversely, any climate agreement that fails to satisfy at least one of the requirements will experience free riding in one or more forms. Consider the Kyoto Protocol. Kyoto 1 seems to have achieved perfect compliance levels; indeed, all Annex B countries met or even exceeded their emissions reduction or limitation targets in the first commitment period. ${ }^{1}$ Nevertheless, when Kyoto 1 expired in 2012 global emissions were approximately $50 \%$ higher than they were in 1990 (Kyoto's baseline year). The reason is that Kyoto 1's effectiveness was hampered by at least four forms of free riding (Hovi, Skodvin, \& Aakre, 2013). First, a few countries-most notably the United States-failed to ratify. Second, one country-Canada-essentially ignored its emissions reductions commitment until it withdrew from the agreement in 2011. Third, some economies in transition participated with extremely shallow targets that they could easily meet or exceed even without implementing any measures specifically intended to curb emissions (the hot air problem). Finally, the developing countries ratified without any binding target for emissions reductions or limitations.

${ }^{1}$ http://phys.org/news/2016-06-kyoto-analysis-compliance.html
We do not dispute that even an agreement that falls somewhat short of fulfilling all three requirements can make a difference, by causing global emissions to become lower than they would have been without the agreement. However, no agreement that falls significantly short of fulfilling one or more requirements can even come close to solving the climate change problem.

An agreement can be effective in the short and/or in the long term. Short-term effectiveness concerns the extent to which the agreement is effective in its own lifetime (here defined as the first 5-year period). Longterm effectiveness concerns the extent to which the agreement triggers future actions that enhance effectiveness in a longer time perspective (beyond the first 5-year period).

The Paris Agreement includes both individual and collective goals. Each party reports a nationally determined contribution (NDC), which constitutes that party's individual goal. Two key collective goals in the Paris Agreement are, first, to keep the rise in global mean temperatures well below $2{ }^{\circ} \mathrm{C}$ and "pursue efforts" to limit warming to $1.5^{\circ} \mathrm{C}$ and, second, to achieve worldwide carbon neutrality sometime between 2050 and 2100 .

An assessment of the agreement's effectiveness thus needs to take into account (1) whether the parties comply with their individual goals, and (2) whether the aggregate effect of a successful implementation of the individual goals enables the parties to reach the agreement's collective goals. In terms of Barrett's three requirements, the latter point concerns whether the parties' (self-determined ${ }^{2}$ ) emissions reduction targets qualify as deep commitments. If the aggregate effect of reaching the individual goals is inadequate to reach the collective goals of the agreement, we further need to consider whether the agreement includes mechanisms that may trigger deeper (more ambitious) commitments over time. The long-term effectiveness of the Paris Agreement thus depends on its ability to preserve ambitious commitments over time-and further deepen them if necessary-while preserving broad participation and high compliance levels.

\section{Short-Term Effectiveness}

In this section, we consider the short-term effectiveness of the Paris Agreement. We do so by assessing how this Agreement fares regarding participation, the depth of participating countries' commitments, and the prospects for achieving high compliance levels. Because we expect compliance to be the Achilles' heel of the Paris Agreement, we place more emphasis on the last requirement than on the first two.

\footnotetext{
${ }^{2}$ In contrast to the Kyoto Protocol, where the parties' individual goals were negotiated (a "top-down approach"), the parties' individual goals in the Paris Agreement are self-determined (a "bottom-up" approach).
} 
The Kyoto Protocol was ratified by nearly all countries. However, after the United States denounced the agreement, Kyoto imposed an emissions reduction or limitation target on only 37 ratifying countries (36 after Canada's withdrawal in 2011). Moreover, these 37 countries were responsible for less than $20 \%$ of global emissions. In this sense, participation in Kyoto was rather limited.

In contrast, a major strength of the Paris Agreement is its broad participation. In Paris, 195 countries consented to the Agreement's adoption and by 1 March 2016, 165 countries-including major emitters such as China and the United States-had submitted their NDCs under the Agreement. ${ }^{3}$ It is thus fair to say that participation is far broader in the Paris Agreement than it was in the Kyoto Protocol.

In Kyoto, Annex I countries committed to reducing emissions about 5\% below 1990 levels in the first commitment period. Many of these countries have made considerably deeper commitments under the Paris Agreement. For example, the European Union has committed to reducing emissions $40 \%$ below 1990 levels by 2030. Moreover, the non-Annex I countries have now joined the Annex I countries in making commitments.

Some countries' NDCs are formulated in a way that makes it challenging to determine whether and, if so, to what extent their fulfilment requires emissions reductions beyond business as usual. Consequently, it is not easy to determine the average depth of the commitments made under the Paris Agreement. However, observers seem to think that the current NDCs, if fully implemented, will curb global warming to somewhere between $2.7^{\circ} \mathrm{C}$ and $3.0{ }^{\circ} \mathrm{C}$ above preindustrial levels, down from the $3.6^{\circ} \mathrm{C}$ expected to result with the policies already in place before (and not including) Paris (Kinver, 2015). Thus, a substantial gap remains between the Agreement's collective aims and the sum of the parties' individual NDCs.

An important question is whether the current NDCs will be fully implemented. Under Paris, NDCs are not legally binding. Hence, one may well question whether it is meaningful to speak of noncompliance if a country fails to fulfil its NDC. However, for lack of better terms, we will nevertheless use the terms "compliance" and "noncompliance".

Compliance with an international agreement depends on many factors, of which we will here briefly consider three. The first is whether the agreement concerned aims to solve a coordination problem or a collaboration problem (Stein, 1990). While countries participating in an agreement of the former type do not face any incentive for noncompliance, countries participating in an agreement of the latter type do (see, for example, Keohane \& Oppenheimer, 2016).

${ }^{3}$ NDCs submissions are available at: http://www4.unfccc.int/ submissions/indc/Submission\%20Pages/submissions.aspx
The climate change problem is a collaboration problem; indeed, it may well be the most challenging collaboration problem ever (Barrett, 2003).

The second factor concerns the depth of the parties' commitments. ${ }^{4}$ A shallow commitment does not require any costly behavioural change. In contrast, implementing a deep commitment might entail very substantial costs (Downs, Rocke, \& Barsoom, 1996). Nearly all economic activity entails GHG emissions (Barrett, 2003). Thus, deep commitments in a climate agreement will be very costly to implement. The deeper the commitments, the greater the costs involved, and the greater the risk of noncompliance (other things being equal).

The third factor has to do with the presence or absence of enforcement measures. In general, the implementation of a climate agreement may be influenced through at least four main types of compliance mechanisms: (1) pressure from domestic stakeholders (including through domestic courts), (2) informal enforcement by other countries, (3) facilitation by international institutions, and (4) enforcement by international institutions. ${ }^{5}$ While Kyoto relied on all four types, it seems that Paris will only rely on the first three.

The Paris Agreement requires each country to report to other countries - and to the public-its progress in implementing its NDC. It also includes an ambition to "track progress towards the long-term goal through a robust transparency and accountability system". ${ }^{6}$ However, Paris provides no material consequences to be implemented against a country that fails to fulfil its NDC. Work is currently underway to develop a compliance system; however, Paris specifically states that any compliance measures should be "expert-based and facilitative in nature and function in a manner that is transparent, non-adversarial and non-punitive".

It is well known that compliance with international environmental agreements is generally good, despite that few such agreements include potent enforcement measures (Chayes \& Chayes, 1995). However, it is far from clear that these findings are relevant for deep climate agreements, where the costs of compliance are

\footnotetext{
${ }^{4}$ This means that commitment depth influences the Agreement's effectiveness both directly (a positive effect) and indirectly (via reduced compliance, a negative effect). The net effect therefore depends on the size of these direct and indirect effects.

5 For example, the 1989 Montreal Protocol on Substances that Deplete the Ozone Layer, which is widely regarded as a very successful treaty, includes a possibility of enforcement in the form of trade restrictions against nonparticipating and noncompliant countries (e.g., see Aakre, Helland, \& Hovi, 2014). While these enforcement measures have never been used, anecdotal evidence suggests that their existence have been important for boosting participation as well as compliance (Brack, 2003, p. 220).

${ }^{6}$ See http://ec.europa.eu/clima/policies/international/negotia tions/paris/index_en.htm
} 
likely to be much larger than in other international environmental agreements.

Because NDCs are not legally binding, enforcement through domestic legal action is also unlikely. Moreover, judged by Canada's experience after its withdrawal from Kyoto, we should not expect much informal enforcement by other members if a country fails to deliver on its NDC or even withdraws from the Paris agreement.

Thus, what remains is the possibility of naming and shaming by domestic and international politicians and pressure groups. The risk of such naming and shaming did not deter the United States from denouncing the Kyoto Protocol in 2001. Nor did it deter Canada from withdrawing 10 years later. It therefore seems pertinent to question whether the anticipation of informal enforcement will suffice to induce all (or even most) of the 195 parties to the Paris Agreement to implement their NDCs. Technically, failure to do so may not result in noncompliance; it may equally well end in the countries concerned pulling out of the agreement (similar to Canada's withdrawal from Kyoto).

Proponents of the management school provide a forceful argument that the design of international enforcement measures is 'a waste of time', because states are (according to this school) largely motivated by international norms rather than by self-interest (Chayes \& Chayes, 1995). ${ }^{7}$ They also argue that simply doing the best one can to reach compliance is efficient, because constantly looking for opportunities to act as a free rider would consume considerable resources.

Concerning climate change, however, the record for commitments without international enforcement is not impressive. While participants in the 1988 Toronto conference collectively aimed to reduce global $\mathrm{CO} 2$ emissions $20 \%$ below 1988 levels by 2005, global emissions actually increased more than 30\% between 1988 and 2005. As noted by Barrett (2008, p. 240), the problem with such global targets is that "everyone is responsible for meeting them-meaning, of course, that no one is responsible for meeting them". Barrett's words also apply to the Paris Agreement's collective goal of stabilizing the global mean temperature at no more than $2{ }^{\circ} \mathrm{C}$ above preindustrial levels, while pursuing efforts to limit warming to $1.5^{\circ} \mathrm{C}$. Indeed, the Paris Agreement's collective goal also suffers from the problem that the global mean temperature partly depends on natural variations; hence, it is even less under the control of the parties than global emissions are.

A better strategy might be to aim for individual targets, and the Paris Agreement specifies individual targets in the form of NDCs. However, the record concerning compliance with individual non-binding emissions

\footnotetext{
7 Following Elster (1989, pp. 98-99), we define a norm as an imperative that is not outcome-oriented. A norm is social if it is shared by several actors and partly sustained by other actors' approval or disapproval.
}

reduction targets is not good either. After the Toronto conference, Austria, Denmark, Italy, and Luxembourg stated that they would meet the Toronto target individually by reducing their own emissions $20 \%$ below 1988 levels by 2005 . None of them did. Other individual targets have also been missed (Barrett, 2008). ${ }^{8}$ Although much has changed since the 1980s, it is far from clear that we can take it for granted that all countries will fulfil their NDCs under the Paris Agreement.

Assuming that enforcement matters, the countries most likely to comply with Paris are the EU members. The reason is that the EU controls a number of enforcement measures of its own that might be used to spur its members to fulfil their targets.

A way to circumvent the need for enforcement could be to design a climate agreement in such a way as to transform the climate change collaboration problem into a coordination problem. Some agreements that introduce a technology standard in the presence of network externalities might serve as an example (see Barrett, 2003). However, the Paris agreement makes little (if any) attempt at pursuing this strategy.

In summary, the Paris Agreement scores high on participation and scores reasonably high on depth (although assessing such depth is challenging). Thus, concerning short-term effectiveness, the main issue is to what extent the countries participating in Paris will actually fulfil their NDCs. Whereas some countries (such as the EU countries) may be expected to be compliant, it remains an open question whether a number of other countries will be. However, even with some noncompliance, Paris could end up as a reasonably successful agreement. Lack of enforcement measures may induce some countries to submit deeper NDCs than they would have done otherwise (Victor, 2011). The irony is that the deeper the commitments, the larger the need for enforcement and the less likely that such enforcement will be politically feasible (Aakre \& Hovi, 2010). However, at least in principle, an agreement with deep commitments and only moderate compliance levels might fare better than one with only shallow commitments but full compliance.

\section{Long-Term Effectiveness}

The long-term effectiveness of the Paris agreement depends on (1) whether a successful implementation of the parties' individual goals (the NDCs) enables the parties to reach their long-term goals of the agreement, and (2) whether the agreement includes mechanisms to further deepen commitments over time, while also ensuring high compliance rates and (continued) broad participation.

\footnotetext{
${ }^{8}$ For a complete list of declared targets or commitments undertaken by OECD countries at this time, see Paterson and Grubb (1992, p. 301).
} 
In its adoption of the Paris Agreement, COP21 emphasized its "serious concern" for the "urgent need to address the significant gap between the aggregate effect of Parties' mitigation pledges...and aggregate emission pathways consistent with holding the increase in the global average temperature to well below $2{ }^{\circ} \mathrm{C}$ above pre-industrial levels and pursuing efforts to limit the temperature increase to $1.5{ }^{\circ} \mathrm{C}$ above preindustrial levels" (Decision 1/CP.21, preamble). In the short term, the Paris Agreement does little to close this gap. A key question, therefore, is whether the Paris Agreement includes mechanisms that contribute to closing the gap over time.

The main mechanism to ensure the Agreement's long-term effectiveness is detailed in Article 4, which states that each party "shall prepare, communicate and maintain successive nationally determined contributions [NDCs] that it intends to achieve" (Article 4.2). These successive NDCs "will represent a progression beyond the Party's then current [NDCs] and reflect its highest possible ambition" (Article 4.3, emphasis added). Each party is invited to communicate its NDC, at the latest, when it submits its instrument of ratification, acceptance, approval or accession. Parties are then requested to communicate a new NDC by 2020 and every five years thereafter (Article 4.9; Decision 1/CP.21, paragraphs 21-24).

This mechanism is supported by the Agreement's reporting, transparency, and monitoring provisions. First, a party is obliged to "regularly provide a national GHG inventory and the information necessary to track progress in implementing and achieving its NDC" (Bodansky \& O'Connor, 2016, p. 10), (Article 13.7a, b). Second, parties are required to submit their NDCs to the secretariat at least 9-12 months in advance of the relevant COP/MOP meeting "with a view to facilitate the clarity, transparency and understanding of these contributions". The NDCs are then summarized in a synthesis report prepared by the secretariat (Decision 1/CP.21, paragraph 25; Article 4.9). Third, a monitoring function of sorts is established in the inclusion of provisions for a "global stocktake", which implies that the COP "shall periodically take stock of the implementation of this Agreement to assess the collective progress towards achieving the purpose of this Agreement and its long-term goals" (Article 14.1). Such global stocktaking shall take place every five years beginning in 2023 (i.e., two years before the parties' NDCs are up for their first revision).

So the Agreement does indeed include mechanisms intended to enhance its long-term effectiveness. However, it remains uncertain whether these mechanisms suffice to ensure the positive snowball effect (or race to the top) many participants and observers hope for. This uncertainty is due to two key features of the Agreement.

First, while the Agreement establishes procedural obligations such as the ones mentioned above, it is largely silent regarding the substantive content of the parties' NDCs. For instance, the Agreement includes a general aim "to reach global peaking of [GHGs] as soon as possible" with "rapid reductions thereafter" (Article 4.1), instructs parties that their NDCs will reflect their "highest possible ambition" (Article 4.3), and states that developed country parties "should continue taking the lead by undertaking economy-wide absolute emission reduction targets" (Article 4.4). However, the parties' commitments will continue to be self-determined and may thus, in aggregate, fall well short of reaching the collective $2{ }^{\circ} \mathrm{C}$ long-term goal. If so, the Paris Agreement may, even with full compliance and even in the long term, prove unable to close the gap COP21 expressed its concern about.

Second, and perhaps more importantly, the Agreement's lack of an enforcement mechanism might generate uncertainty concerning some parties' willingness to honour their commitments. A "compliance mechanism" is established to "facilitate implementation and promote compliance with the provisions of this Agreement" (Article 15.1). But this mechanism will almost certainly include no incentives to actively discourage and sanction noncompliance. On the contrary, the Paris Agreement expressly states that the compliance mechanism "shall be...non-adversarial and nonpunitive" (Article 15.2). Thus, parties might be tempted to communicate over-ambitious NDCs-for instance, targets they do not know if they are able to implement, are unlikely to implement, or even do not intend to implement-with impunity. An NDC thus represents little more than a party's good intentions. If there are reasons to doubt a party's sincerity, other parties' willingness to implement ambitious emissions reductions might be weakened accordingly. The lack of an enforcement mechanism, therefore, could limit the Agreement's long-term effectiveness, because it means that even if all parties intend to implement ambitious emissions reductions, they might nevertheless be reluctant to do so simply because they lack confidence in other parties' willingness to honour their commitments. Thus, even if we might see an initial upward cycle of progressively rigorous NDCs, the long-term effectiveness of the Agreement could be modest.

The lack of an enforcement mechanism is arguably the Agreement's main weakness. Yet, this feature might also be the cause of the Agreement's most hailed achievement: participation by a broad scope of countries (including developed countries as well as developing countries and countries with emerging economies) that have set specified emissions reduction or control targets. Indeed, parties may have agreed to join the Agreement with emissions control targets precisely because there is no risk associated with such behaviour. While noncompliance might entail reputational damage, it will not entail immediate material costs. 
The interlinkage between participation, the depth of commitments, and enforcement implies that even if parties were to supplement the Paris Agreement with an enforcement mechanism in the future (there are no indications at present that they will), that might adversely affect the incentive to remain a party and/or the incentive to submit an ambitious NDC. First, with an enforcement mechanism in place, parties that fail to implement their NDCs might withdraw from the Agreement rather than remain a party and suffer the costs of punitive sanctions for noncompliance. Article 28 states that "at any time after three years from the date on which this Agreement has entered into force for a Party, that Party may withdraw from the Agreement" (28.1), and that "any such withdrawal shall take effect upon expiry of one year from the date of receipt by the Depositary of the notification of withdrawal" (28.2).

Second, with an enforcement mechanism in place, parties might feel inclined to submit less ambitious NDCs, both to be certain of their ability to meet the targets (and hence avoid punitive sanctions) and to enable them subsequently to submit progressively more rigorous NDCs at low cost. In these scenarios, therefore, rather than seeing the positive snowball effect everyone hopes for, we might see that the Agreement will have decreasing participation and an increasing gap between the aggregate effect of parties' mitigation pledges and the required aggregate emission pathway to reach the $2{ }^{\circ} \mathrm{C}$ goal.

While the Paris Agreement includes provisions intended to increase its effectiveness over time, no incentives are included to support these provisions and to ensure their intended effect. The long-term effectiveness of the Paris Agreement thus entirely depends on other factors.

One such factor might be the reputational damage that could be associated with nonparticipation and noncompliance. Bodansky and O'Connor suggest that "states risk greater costs to their reputation and to their relations with other states if they violate a treaty commitment than a political commitment, making noncompliance less attractive" (2016, p. 16). But he also suggests that 'the inclusion of transparency and accountability mechanisms in the Paris agreement could accomplish the same result. By making it more likely that poor performance will be detected and criticized, these mechanisms will raise the reputational costs of failing to achieve one's NDC' (2016, pp. 16-17). Yet, as we have already seen, the risk of reputational costs does not seem to have significantly influenced the United States' decision not to ratify Kyoto 1, Canada's decision to withdraw from it, or the decision of countries such as Belarus, Japan, New Zealand, Russia, and Ukraine not to sign on to Kyoto 2 .

Another factor concerns the market responses to the Agreement. If the Paris Agreement generates new investment patterns in key global markets, for instance by accelerating investments in "green energy" and decelerating investments in fossil energy, it could have significant implications for future emissions reductions. While experts see it as "likely" that the Paris Agreement "will accelerate investments in technologies like renewable energy and electric vehicles", the International Energy Agency forecasts that "fossil fuels will still account for about 75 percent of energy demand in 2030, with coal hitting a plateau, oil growing slightly and gas surging" (Campbell, 2015).

Finally, as noted, the long-term effectiveness of the Paris Agreement mostly depends on the extent to which parties trust each other to implement their commitments. In particular, the Paris Agreement's long-term effectiveness will likely be significantly influenced by the response of large global emitters. In the next section, we consider the likelihood that the United States will act as a leader under the Paris Agreement.

\section{The United States-A Pivotal Actor in the Paris Agreement}

The United States is a crucial player in the Paris Agreement, not only because it is the world's second largest emitter of GHGs but also because it has a special role to play in terms of triggering action from other countries. As described above, the Agreement relies inherently on vagueness in its specification of commitments, compliance requirements and the ratcheting-up mechanism (see also Keohane \& Oppenheimer, 2016). While such vagueness was necessary diplomacy for forging the Agreement itself and attract broad participation, it locks success to reliance on key countries to go first and set the stage for a snowball effect (or race to the top). As argued by Underdal (1994, pp. 179-180), "the more complex the negotiation setting (that is, the larger the number of actors and the number and 'intricacy' of issues), the more likely that some actors will emerge as leaders and others as followers..., and the more critical leadership becomes as a determinant of success".

Arguably, the United States must play an important role in such leadership for at least two reasons. First, as the largest economy in the world and the second largest carbon emitter the United States is often pointed to as a key actor because of its major historical responsibilities for the climate change problem (e.g. World Resources Institute, 2016). What happens with U.S. climate policy has an effect for the entire world. Second, in the history of international climate negotiations the United States has often played the role as crucial laggard, blaming lack of participation by all major emitters and flawed treaty design for its own non-participationfor instance in the Kyoto Protocol. Experience thus indicates that for any comprehensive international climate agreement to work, it is vital that the world's most powerful country shows interest in participation and compliance with its pledges. If a pivotal actor like 
the United States should fail to implement its commitments, it will likely negatively affect other parties' incentives to adopt and implement ambitious NDCs.

In the following pages, we analyse the role that the United States took at COP 21 and in the months preceding the conference to secure the adoption of a bottom-up agreement. We argue that the United States took several crucial steps to influence the outcome. We also analyse the domestic politics underlying the U.S. position at COP 21, to enable an evaluation of the prospects for the country to deliver on its Paris pledges. The dynamic between domestic politics and international negotiation positions is important in order to understand the scope for acceptance of international commitments in all countries. In the U.S. case this dynamic is influenced by the separation of powers in the political system that gives the president great freedoms in international negotiations, but allows the Senate decisive powers in issues of treaty ratification and funding of new policy programs. Hence, the interaction between the executive and legislative branches of government defines the scope for U.S. pledges at Paris, as well as the prospects to fulfil them. It helps explain why the United States can come to play an important role for the success of the Paris Agreement if it engages in a role as first mover (in a race to the top), but can also explain why in a difficult collaboration problem like climate change the United States may have difficulties in taking on such leadership.

In Paris, U.S. diplomacy and personal engagement by President Barack Obama and Secretary of State John Kerry helped craft compromises that were necessary for the adoption of the Agreement. Importantly, Obama engaged with China's President Xi through crucial bilateral contact in the months before the Paris meeting, paving the way for support of the Agreement by both countries (Goldenberg, 2014; Henderson, 2015). At the Paris meeting, President Obama said: "I've come here personally, as the leader of the world's largest economy and the second-largest emitter, to say that the United States of America not only recognizes our role in creating this problem, we embrace our responsibility to do something about it" (White House, 2015). The Obama administration acknowledged that the United States can play a key role in inspiring and convincing other countries to address their GHG emissions, and committed to reducing U.S. GHG emissions 26 to $28 \%$ below 2005 levels by 2025, premised on numerous domestic policy measures that have been or are to be implemented (Bang \& Schreurs, 2016). Ambitious domestic investments in clean energy, energy efficiency programs, and new federal regulations limiting carbon emissions from power plants are among the climate policies initiated by the Obama administration.

The Obama administration has fought hard for changes in domestic climate policy. At the outset of his first term, President Obama pushed for the U.S. Con- gress to pass climate legislation. Several bills were debated, and in June 2009 Congressmen Waxman and Markey's American Clean Energy and Security Act narrowly passed a vote in the House yet later died in the Senate (Bang \& Skodvin, 2014). Voting on this controversial bill largely followed party lines, reflecting deep and bitter polarization between Republicans and Democrats (Skocpol, 2013). No climate bill has been debated in the U.S. Congress since, and with Republican majorities in both the House and the Senate after the 2012 elections, climate legislation was no longer on the congressional agenda. In his second term, therefore, President Obama decided to use executive powers to circumvent the congressional gridlock on climate policy. Acting on the U.S. Supreme Court's ruling from 2009, which identified carbon emissions as a pollutant causing risks to the health and welfare of citizens, Obama ordered the Environmental Protection Agency (EPA) to develop regulations under the Clean Air Act to cut $\mathrm{CO}_{2}$ emissions in the power sector by $32 \%$ by 2030 (Bang, 2015). The EPA worked with stakeholders and state-level regulators over two years (2013-2015) to set up regulations-the Clean Power Plan-that engage states to design individual plans for cutting carbon emissions from power plants. States are assigned individual emissions reduction targets, and are encouraged to find policy solutions adapted to local circumstances to minimize negative effects on industry and consumers (EPA, 2015).

The Clean Power Plan (CPP) is extremely controversial among policymakers at both the federal and the state levels. The controversy centres on whether the Clean Air Act gives the president and the EPA the authority to introduce wide-ranging regulations for $\mathrm{CO}_{2}$ emissions without involving the U.S. Congress. Opponents at the federal and state levels have sought to put up barriers. Republican leaders in Congress have vowed to cancel the CPP at the first opportunity. Senate Majority Leader Mitch McConnell (Republican from Kentucky) encouraged states not to start developing plans, arguing that they would be wasting resources since the CPP will likely be removed either through congressional action by the Republican majority or through the courts (Cama, 2016). Several votes in Congress in 2013-2015 tried to remove the EPA's authority on the issue; however, those bills that passed were vetoed by the president. In October 2015, a coalition of 26 states - many of which depend heavily on coal for power generation-brought litigation against the EPA, arguing that the CPP represented a "power grab" by the federal government over state-level electricity systems that would be excessively burdensome for the states' economies (Bang \& Schreurs, 2016). A significant blow to the Obama administration's climate policy came in February 2016 when a 5-4 decision in the Supreme Court stayed implementation of the CPP until judicial review of its legality. The Court's decision illus- 
trates the fragility of the Obama administration's climate policy and the significant role of judicial review when executive power is used to impose policy in a controversial field. If the Supreme Court decides to hear the case, its ruling might influence the future of the CPP as well as the U.S. ability to fulfil its commitment in the Paris Agreement.

Many U.S. states have put on hold any effort to develop state implementation plans for adhering to the CPP, while other states are pursuing climate action regardless of the uncertainty surrounding the plan's future (C2ES, 2016). Clearly, deep polarization in U.S. climate policy affects the United States' ability to live up to the promises it made in Paris. Without a firm domestic policy strategy, like the CPP or some other federal climate policy, investors and business owners will have weak incentives to make long-term business decisions that include a pathway to a low carbon economy. Moreover, the U.S. NDC under the Paris Agreement will be less credible. U.S. political parties greatly disagree on the importance of climate policy action. Most Democrats accept that climate change is a serious problem that requires political action to reduce emissions. Most Republicans, on the other hand, are not committed to addressing the climate change problem, because they do not believe in the science or because they think it is premature to risk the potential economic hardship that climate action might bring (Leiserowitz et al., 2016).

These different views regarding the need for climate policy action convey the level of willingness to recognize the Paris Agreement as a priority for the United States. While President Obama and a clear majority in the Democratic Party are fully committed, Republican leaders reacted very differently to the Agreement's adoption. The immediate reaction of leading Republicans after COP 21 indicated a looming fight over the commitment to the Paris Agreement. Senate Majority Leader Mitch McConnell said, "Obama is making promises he can't keep" and should remember that the Agreement "is subject to being shredded" after the 2016 election. With reference to the presidential election, McConnell said the Agreement could be reversed if the Republicans win the White House (Freking, 2015). Republicans argued that the deal is simply politically binding, not judicially binding, and hence barely worth any serious attention. Congressman Ed Whitfield (Republican from Kentucky) described the Paris Agreement as merely a "signal" of the Obama administration's preferences rather than a treaty. He said, "While some may claim the resulting deal is a grand triumph, the bottom line is that this was a nonbinding political document that does not impose any new obligation on the United States". He added that Obama "misled the international community in Paris" (Chemnik, 2016).

The Republican Party Convention in 2016 adopted a political platform that explicitly rejects any form of federal carbon price, and pledged to disengage the
United States from any further involvement with the "non-binding" Paris Agreement. The Democratic Party Convention in 2016 supported both a carbon tax, continuation of Obama's climate policy programs, and fulfilment of pledges made in Paris. Presidential candidates Donald Trump and Hillary Clinton mirror their party's opposing views, hence representing starkly different ways forward for U.S. climate policy.

In sum, deep political polarization over climate change prevents the United States from sending a clear signal to other countries that it is ready to address carbon emissions seriously and to lead the international process envisioned by the Paris Agreement. Potentially, the 2016 presidential election could upset Obama's climate leadership and put the United States back in a position where no credible federal climate policy initiatives exist. For the time being, therefore, the potential and willingness for the United States to lead is unclear.

\section{Conclusion}

To build an effective climate agreement and to strengthen it over time, states might rely on two main types of factors-norms and incentives. An ideal agreement would ensure that both norms and incentives push the parties to make serious efforts to reduce emissions and to gradually reinforce those efforts.

The Paris Agreement currently relies disproportionately on norms, while doing little to restructure states' incentives so as to deter free riding. Norms and incentives thus pull in opposite directions, meaning that the outcome will depend on the force of each factor. Because virtually all economic activity entails emissions of GHGs, the incentive to free ride is much stronger in the context of climate change than in the context of other international environmental cooperation. Unsurprisingly, therefore, the historical record of climate change cooperation suggests that the force of incentives has thus far outweighed that of norms. Judged by this record, the Paris Agreement may well suffer a fate similar to Kyoto's. Kyoto, too, aimed for a series of 5-year periods with new and more ambitious commitments in every period. Yet already by the end of the first period, this architecture was clearly not viable.

On a more optimistic note, norms can change. For example, the Paris Agreement shows that today's interpretation of the common-but-differentiatedresponsibilities norm differs from that of the 1990s and 2000s. Consequently, the cards are now stacked somewhat less in favour of incentives than they were then. Domestic and international norms may well continue to develop such that it becomes increasingly difficult for individuals, firms, and states to ignore pleas to limit and reduce their carbon footprints. In addition, technological progress may gradually lessen abatement costs. Such developments would further favour norms over incentives. Finally, if major emitters such as the 
United States prove able and willing to take the lead, it might further strengthen cooperative norms and limit other countries' costs of compliance. Such developments might ultimately pave the way for a transformation from a logic of consequences to a logic of appropriateness in the field of climate change (Mitchell, 2015).

So far, however, deep political polarization has represented a significant barrier to U.S. leadership on climate change. Thus, while the Paris Agreement could become the start of a race to the top that sets the world on a path towards solving the climate change problem, it might also end as a flop, much like the Kyoto Protocol did. The latter outcome is particularly plausible if the United States and other major emitters prove unable or unwilling to lead.

\section{Acknowledgments}

We thank the editorial team at Politics and Governance and three anonymous reviewers for helpful comments.

\section{Conflict of Interests}

The authors declare no conflict of interests.

\section{References}

Aakre, S, Helland, L., \& Hovi, J. (2014). When does informal enforcement work? Journal of Conflict Resolution. doi:10.1177/0022002714560349

Aakre, S., \& Hovi, J. (2010). Emission trading: Participation enforcement determines the need for compliance enforcement. European Union Politics, 11(3), 427-445.

Bang, G. (2015). The United States: Obama's push for climate policy change. In G. Bang, A. Underdal, \& S. Andresen (Eds.), The domestic politics of global climate change. Key actors in international climate cooperation. Cheltenham: Edward Elgar Publishing.

Bang, G., \& Skodvin T. (2014). U.S. climate policy and the shale gas revolution. In T. Cherry, J. Hovi, \& D. McEvoy (Eds.), Toward a new climate agreement: Conflict, resolution and governance. London: Routledge.

Bang, G., \& Schreurs, M. A. (2016). The United States: The challenge of global climate leadership in a politically divided state. In R. K. Wurzel, J. M. Connelly, \& D. Liefferink (Eds.), Still taking a lead? The European Union in international climate change politics. London: Routledge.

Barrett, S. (2003). Environment and statecraft. Oxford: Oxford University Press.

Barrett, S. (2008). Climate treaties and the imperative of enforcement. Oxford Review of Economic Policy 24(2), 239-258.

Bodansky, D., \& O'Connor, S. D. (2016). The legal character of the Paris Agreement. Manuscript submitted for publication.
Brack, D. (2003). Monitoring the Montreal protocol. In T. Findlay (Ed.), Verification yearbook 2003 (pp. 209226). London: VERTIC.

Brun, A. (2016). Conference diplomacy: The making of the Paris Agreement. Politics and Governance, 4(3), 115-123.

Cama, T. (2016). McConnell tells states to stop planning for EPA climate rule. The Hill. Retrieved from http://thehill.com/policy/energy-environment/2737 74-mcconnell-tells-states-to-stop-planning-for-epaclimate-rule

Campbell, M. (2015, December 14). Big oil, make way for big solar. The winners and losers in Paris. Bloomberg. Retrieved from http://www.bloomberg.com/news/ articles/2015-12-14/big-oil-make-way-for-big-solarthe-winners-and-losers-in-paris

Center for Climate and Energy Solutions (C2ES). (2016). Map: State action on the clean power plan. Retrieved from http://www.c2es.org/us-states-regions/policymaps/state-action-clean-power-plan

Chayes, A., \& Chayes, A. H. (1995). The new sovereignty. Cambridge, MA: Harvard University Press.

Chemnik, J. (2016). Will Republicans seek to undermine Paris agreement? The politics surrounding the landmark global climate deal are murky in this election year. Scientific American, January 6. Retrieved from http://www.scientificamerican.com/article/willrepublicans-seek-to-undermine-paris-agreement

Dimitrov, R. (2016). The Paris agreement on climate change: Behind closed doors. Global Environmental Politics. doi:10.1162/GLEP_a_00361

Downs, G. W., Rocke, D. M., \& Barsoom, P. N. (1996). Is the good news about compliance good news about cooperation? International Organization, 50(3), 379406.

Elster, J. (1989). The cement of society. A study of social order. Cambridge: Cambridge University Press.

Environmental Protection Agency (EPA). (2015). Clean power plan. Retrieved from http://www2.epa.gov/ cleanpowerplan

Freking, K. (2015). Republican lawmakers vocal in opposition to climate deal. The Huffington Post. Retrieved from http://www.huffingtonpost.com/entry/republi can-lawmakers-vocal-in-opposition-to-climatedeal_us_566d6165e4b0e292150e2feb

Goldenberg, S. (2014). Secret talks and a private letter: How the US-China climate deal was done. The Guardian. Retrieved from http://www.theguardian. com/environment/2014/nov/12/how-us-china-clima te-deal-was-done-secret-talks-personal-letter

Henderson, G. (2015, September 15). Chinese and U.S. cities, states and provinces announce climate targets and extensive cooperation. China FAQs: The Network for Climate and Energy Information. Retrieved from http://www.chinafaqs.org/blog-posts/chinese-andus-cities-states-and-provinces-announce-climatetargets-and-extensive-coopera 
Hovi, J., Skodvin, T. \& Aakre, S. (2013). Can climate change negotiations succeed? Politics and Governance, 1(2), 138-150.

Keohane, R. O., \& Oppenheimer, M. (2016). Paris: Beyond the climate dead end through pledge and review? Politics and Governance, 4(3), 142-151.

Kinver, M. (2015, December 14). COP21: What does the Paris climate agreement mean for me? $B B C$. Retrieved from http://www.bbc.com/news/scienceenvironment-35092127

Leiserowitz, A., Maibach, E., Roser-Renouf, C., Feinberg, G., \& Rosenthal, S. (2016). Politics and global warming. New Haven, CT: Yale Program on Climate Change Communication.

Mitchell, R. B. (2015). The problem structure of climate change and the need for a discursive transition. Retrieved from https://clas-pages.uncc.edu/inss/annual -meetings/2015-meeting/conference-presentations/ bend-or/the-problem-structure-of-climate-changeand-the-need-for-a-discursive-transition

Paterson, M., \& Grubb, M. (1992). The international politics of climate change. International Affairs, 68(2), 293-310.
Simmons, B. (1998). Compliance with international agreements. Annual Review of Political Science, 1(1), 75-93.

Skocpol, T. (2013, February 14). Naming the problem: What it will take to counter extremism and engage Americans in the fight against global warming. Paper presented at the Symposium "The Politics of America's Fight Against Global Warming, Harvard University, Cambridge, MA.

Stein, A. A. (1990). Why nations cooperate. Ithaca: Cornell University Press.

Underdal, A. (1994). Leadership theory. In W. Zartman (Ed.), Rediscovering the arts of management. San Francisco, CA: Jossey-Bass Publishers.

Victor, D. (2011). Global warming gridlock. Cambridge, MA: Cambridge University Press.

White House. (2015). Remarks by President Obama at the first session of COP21. Retrieved from https:// www.whitehouse.gov/the-press-office/2015/11/30/ remarks-president-obama-first-session-cop21

World Resources Institute. (2016). The United States. Retrieved from http://www.wri.org/our-work/topics/ united-states

\section{About the Authors}

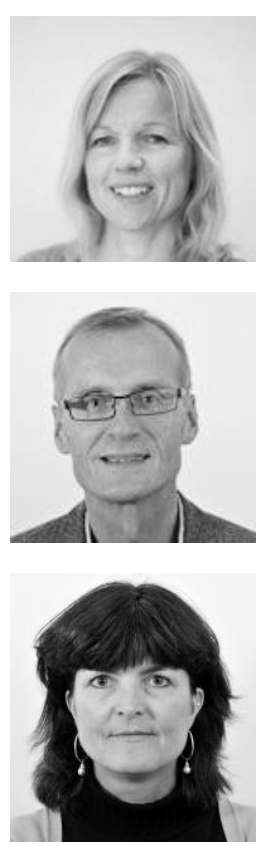

Guri Bang is Research Director at the Center for International Climate and Environmental Policy, Oslo (CICERO). Her research focuses on comparative energy and climate policy; low-carbon energy transitions; international climate politics, and U.S. climate and energy politics. She is leading research projects on domestic climate policy development in the U.S., EU, China, India, Brazil, Japan, and Russia for the Norwegian Center for Strategic Challenges in International Climate Policy (CICEP) and the Research Council of Norway.

Jon Hovi is professor of political science at the University of Oslo. His research focuses on the design of international agreements, particularly the aspects pertaining to participation, compliance, and enforcement. Other research interests include the effectiveness of economic sanctions as well as strategic aspects of international and domestic armed conflict.

Tora Skodvin is professor of political science at the University of Oslo. Her main areas of interest include international negotiation with a particular focus on the international negotiations of climate change, the role of non-state actors in international climate policies and the domestic-international interface of U.S. and EU climate and energy policies. 